\title{
EL PALENCIANISMO HISTORIOGRÁFICO DE MANUEL REVUELTA
}

\author{
ANTONIO ASTORGANO ABAJO ${ }^{1}$
}

RESUMEN: Dentro de la extensa producción historiográfica del jesuita Manuel Revuelta (500 escritos aproximadamente), la temática sobre la Historia de la Provincia de Palencia ocupa un lugar preferente (unos 80). En el presente trabajo analizamos y clasificamos lo publicado sobre el tema, lo principal en la revista Publicaciones de la Institución Tello Téllez de Meneses (PITTM), ligada a la Diputación Provincial de Palencia. Queda patente el permanente cariño que el jesuita mantuvo durante toda su vida a sus raices familiares palentinas.

Palabras clave: Manuel Revuelta González; Publicaciones de la Institución Tello Téllez de Meneses (PITTM); Historia de Palencia; Compañía de Jesús restaurada.

\section{The historiographic palencianism of Manuel Revuelta}

ABSTRACT: Within the extensive historiographic production of Jesuit Manuel Revuelta (approximately 500 writings), the theme of the History of the Province of Palencia occupies a preferential place (about 80). In this paper we analyze and classify what has been published on the subject, the main aspect in the magazine Publicaciones de la Institución Tello Téllez de Meneses (PITTM), linked to the Provincial Council of Palencia. This evidences the permanent affection that the Jesuit maintained throughout his life to his Palencia family roots.

KEY WORDS: Manuel Revuelta González; Magazine Publicaciones de la Institución Tello Téllez de Meneses (PITTM); History of Palencia; restored Society of Jesus.

\section{INTRODUCCIÓN}

En otro lugar hemos mostrado recientemente con cierta amplitud nuestra admiración sobre la obra y persona de nuestro amigo Manuel Revuelta, SJ (Astorgano, 2020). Allí analizamos nuestra relación intelectual durante

1 Real Academica de Extremadura. Correo electrónico: astorgano1950@gmail.com 
25 años y su extensa producción historiográfica. En las pocas páginas que ahora disponemos, simplemente aludiremos a unos de los cuatro campos temáticos en los que el mismo Revuelta clasificó su actividad intelectual: los escritos relacionados con la Provincia de Palencia, temática en la que nos introdujimos de manera paulatina y casi insensiblemente, y a la que hemos dedicado media docena larga de estudios (Astorgano, 2015; 2016a; 2016b; 2017a; 2017b; 2018; 2019a; 2019b), relacionados con el jesuita expulso Juan José Tolrá, personaje al que Revuelta terminó admirando por su afán restauracionista de la Compañía y por su palencianismo.

Revuelta solía comentar que:

el haber nacido en un pueblo como Población de Campos le predispone a uno a hacerse historiador. En un pueblo como el mío la historia es como el campo. Te rodea por todas partes. Casi es lo único que queda. Población, como su nombre indica, es una repoblación de los primeros tiempos de la reconquista, fue cabeza de la bailía de la Orden de Malta, tiene dos ermitas románicas a la vera del camino de Santiago, y una iglesia monumental con obras de arte de gran calidad [...]. La historia se te hace familiar en un pueblo así (Madrid, 17 de noviembre de 2011) $)^{2}$.

La afición a la historia de Palencia fue perenne en Revuelta, quien recibió el espaldarazo como historiador y la maduración como docente e investigador entre 1968 y 1972, periodo en el que elaboró la tesis doctoral, bajo la dirección de Vicente Palacio Atard, sobre el Trienio Constitucional. La lectura de las actas de las Cortes de 1821 le despertó el interés por la historia de Palencia, que entonces estuvo a punto de desaparecer como provincia. De manera parecida, los catálogos de los fondos la Orden de Malta le dieron pistas para investigar la bailía de Población de Campos. Por lo tanto, la temática palentina estuvo desde el principio entre sus afanes investigadores, continuando hasta su muerte, contagiándola a sus amigos, como es nuestro caso, a través del jesuita restaurador Juan José Tolrá (1739-1830).

Mi progresivo interés por los temas palentinos, estimulado por Revuelta, es bastante tardío y centrado en torno al citado Tolrá, al que hasta 2010 yo no le había prestado excesiva atención, aunque esbocé su biografía en la Biblioteca jesuítico-española de Hervás (2007, pp. 531-532). Con motivo de las efemérides de la Constitución de las Cortes de Cádiz de 1812 el mundillo historiográfico planteó diversas reuniones, y nosotros pensamos ir a algunas

2 En su momento Revuelta me remitió este discurso, con motivo de un homenaje que se le hizo, aunque no recuerdo el motivo ni si se llegó a publicar. Probablemente lo dijo en la presentación del libro: Revuelta (2010), Historia y espíritu en tierras palentinas. 
hablando sobre las reclamaciones que algunos jesuitas expulsos dirigieron a dichas Cortes, clamando contra la injusticia que supuso la expulsión de abril de 1767, que fundamentalmente fueron dos: la encabezada por el sangüesino Francisco Javier Mariátegui (1812)ํy y por Juan José Tolrá (Tolrá et al., 1812). Empecé con la tarea y en una de nuestras conversaciones telefónicas, a principios de 2010, salió a relucir el asunto. Revuelta me comentó que su discípulo José Martínez Millán iba a organizar un congreso sobre jesuitas (Martínez Millán et al., 2012), que lo había invitado a inaugurarlo o clausurarlo; que pensaba disertar sobre los jesuitas y las Cortes de Cádiz y que, lógicamente, tenía que hablar de la reclamación de Juan José Tolrá, que además era palentino de adopción. También Revuelta le había sugerido que yo fuese invitado a participar en dicho congreso. Obviamente no podíamos ir al citado cónclave hablando de lo mismo. Le propuse que él tratase de las reclamaciones posteriores a la promulgación de la Constitución de Cádiz, y que yo lo hiciese con las anteriores a dicha fecha. Así yo me fijaría en la instancia de Mariátegui y él en la encabezada por Tolrá. Al final Revuelta (2012) nos dio una magistral lección en la clausura de dicho macro congreso considerando a las Cortes de Cádiz como una encrucijada entre la antigua y la nueva Compañía, y yo decidí no tratar el tema de las restauración de la Nueva Compañía y hacerlo sobre la pintura al encausto grecolatina restaurada por el abate Vicente Requeno (Astorgano 2012, pp. 863-924), que nada tenía que ver con la disertación de Revuelta ${ }^{4}$. Entre tanto publiqué dos estudios sobre Mariátegui, uno en el «Coloquio internacional. Del mundo hispánico a la consolidación de las naciones. 1808-1940», celebrado en Tlaxcala en agosto de 2010 (Astorgano, 2010), y otro en la revista Príncipe de Viana (Astorgano, 2011), citado con elogio por Revuelta (2012, pp. 1859-1906) en su disertación.

Tanto las reclamaciones como las figuras de Mariátegui y la de Tolrá están suficientemente estudiadas, como para no insistir ahora en ellas, por lo que nos tomamos la licencia de divagar brevemente sobre el palencianismo de Tolrá y Revuelta, en cuyas vidas hallamos cierto paralelismo, sin perder de vista el anacronismo de los dos siglos que separan sus nacimientos $1739 \mathrm{y}$

\footnotetext{
3 Mariátegui (1812), El Ex Jesuita oprimido. Publicado íntegramente con abundantes notas explicativas en Astorgano (2011).

4 Como anécdota, al final de mi intervención hubo un debate, correcto con el académico de Bellas Artes, el jesuita Alfonso Rodríguez G. de Ceballos, en el transcurso del mismo el presidente de la mesa, un lingüista y catedrático de la Universidad Autónoma de Madrid, recientemente elegido miembro de la RAE, sin tener ni idea de Requeno, hizo una impertinente observación que disgustó bastante a Revuelta, según la breve observación que me hizo privadamente al final de la sesión: «no hagas el más mínimo caso a pedantes y currucatos». Acertado consejo.
} 
1936. Paralelismo basado en su profundo jesuitismo, simpatía por la Compañía de Jesús restaurada y sus raíces palentinas.

\section{ESCRITOS DE REVUELTA SOBRE LA HISTORIA DE PALENCIA}

Revuelta concibe la historia como «magistra vitae», para comprender mejor la identidad de personas, pueblos e instituciones, que, en su caso, se centró en dos "grandes querencias: la Iglesia, y dentro de ella la Compañía de Jesús, España y dentro de ella mi tierra palentina» (discurso citado de 17 de noviembre de 2011). Por eso es lógica su pertenencia a la Institución Tello Téllez de Meneses (hoy Academia Palentina de Historia, Letras y Bellas Artes) y las múltiples publicaciones relacionadas con Palencia. En un somero recuento, encontramos cuatro libros, once artículos en libros colectivos, 22 artículos en revistas, media docena de prólogos a libros ajenos y una treintena de recensiones de libros relacionados con Palencia.

Revuelta enumeró toda su producción historiográfica en tres ocasiones: en dos libros: Historia y espíritu en tierras palentinas (Revuelta, 2010), y en Enigmas Históricos (Revuelta, 2017a) y en sus Memorias (Pérez García, 2019)5. A veces cambia en estos recuentos las clasificaciones de su bibliografía, pero siempre las cierra con «Libros sobre la historia de Palencia». Así en Enigmas Históricos, el más fiable de los recuentos, dice: «Mis investigaciones históricas se centran con preferencia en tres campos: la historia de la Iglesia de España (con especial atención al siglo XIX); la historia de la Compañía de Jesús en la edad contemporánea; y la historia de Palencia» (Revuelta 2017a, p. 18).

El volumen historiográfico palentino es importante en relación con el total de lo publicado por Manolo, quien en 2017, siendo ya consciente de su evidente declive físico, cierra sus Enigmas históricos con un apéndice con las «Publicaciones de Manuel Revuelta González» (Revuelta, 2017a, pp. 275-302). Son 482 bien ordenadas cronológicamente, excepto algunas de las recensiones: 20 libros individuales, 66 libros colectivos, 120 artículos en revistas, 31 prólogos, 48 artículos en diccionarios y 196 recensiones. Llama la atención la discrepancia con lo que escribió en sus Memorias, poco antes de morir, donde lamenta el que no se le hubiese hecho un libro-homenaje

5 Agradecemos el envío de algunos fragmentos de las Memorias de Revuelta al P. Antonio Pérez García, testigo de los últimos días y muerte de Revuelta. Hemos procurado conseguir una copia de dichas Memorias, pero el secretario de la Provincia jesuítica de España, el andaluz, hermano Soto Artuñedo, se ha negado, alegando escrúpulos poco convincentes. 
y nos informa de que había hecho dos recuentos de sus publicaciones: «En los libros-homenaje a los profesores no falta la numeración de sus publicaciones. Como a mí nadie me dedicó ese libro, yo mismo hice dos veces el recuento de mis publicaciones» (Pérez García, 2019). Una en el libro Historia y espíritu en tierras palentinas (Revuelta, 2010), en el que se cita un total de 385 títulos (17 libros individuales, 57 colectivos, 22 prólogos, 93 artículos de revistas, 49 artículos en diccionarios y 147 recensiones). Otra en Enigmas históricos (Revuelta, 2017a), donde los títulos suben a 482, casi un centenar más que en 2010 (20 libros, 67 libros colectivos, 120 artículos en revistas, 51 prólogos, 48 artículos en diccionarios, y 196 recensiones). En el momento en que escribe el capítulo de sus Memorias (11 de junio de 2019), los títulos publicados son 472, según Revuelta: libros individuales, 20; colaboración en libros colectivos, 83; artículos en revistas, 89; prólogos en libros ajenos, 98; artículos en diccionarios de Historia, 48; recensiones, 134 (Pérez García, 2019). Respecto al recuento de 2017, sólo coincide en el número de libros (20) y en el de prólogos (48). Discrepancia más incompresible, puesto que a lo largo del bienio 2017-2019 Revuelta continuó publicando. Por ejemplo, colaboró en el homenaje que la Diputación Provincial de Zamora tributó al jesuita y académico Quintín Aldea (Revuelta, 2018), en el que también participamos, a sugerencia del mismo Revuelta. Pero discrepancia comprensible, considerando que el último recuento lo hizo, muy deteriorado físicamente, un mes antes de fallecer.

A las publicaciones palentinas reseñadas en Enigmas históricos (Revuelta, 2017a), debemos añadir, que sepamos, un artículo, «El altar mayor de la iglesia de Santa María Magdalena de Población de Campos» (Revuelta 2017b) y un par de reseñas de libros de temática palentina, Pérez González «Peridis» (2018) y León Palenzuela (2018), aparecidas los dos últimos años de su vida en PITTM.

\subsection{Los LIBROS PALENTINOS DE REVUELTA}

Cronológicamente los estudios palentinos de Revuelta abarcan toda su vida académica. Su primer libro de esta temática es de 1981, Orígenes históricos de la constitución de la Provincia de Palencia (Revuelta, 1981) y el último de 2015, Las tres estancias de Santa Teresa en Palencia (Revuelta, 2015).

En el intermedio apareció Historia y espíritu en tierras palentinas (Revuelta, 2010), donde se recopilan los estudios palentinos más importantes de Manolo. Además sirvió para hacérsele un pequeño homenaje en la Universidad Pontificia Comillas. Probablemente es el libro que publicó con 
mayor gusto, dado su hondo sentir palentino. En su presentación participaron Henar Pizarro, profesora de dicha Universidad, y Rafael Ángel Martínez González, delegado de cultura de Palencia y académico de la ITTM desde 1994. Como era año santo compostelano era obligado mencionar el Camino de Santiago, por lo que el libro se tituló Historia y espíritu en tierras palentinas. Camino de Santiago y otros afanes (Revuelta, 2010). El Camino de Santiago se reduce a los cuatro primeros pueblos palentinos: Boadilla, Frómista, Población de Campos y Revenga. La segunda parte del libro se ocupa de la historia de la Provincia, en cuatro temas: religiosidad tradicional y disidencias, el sindicalismo católico agrario, la figura de Antonio Monedero Martín (1872-1940), propagandista y organizador de los sindicatos católicos agrarios (Monedero, 2003), y el arte perdido y hallado en Palencia. El libro se abre con una dedicatoria muy pensada a sus padres: "A la memoria de mis padres, Fortunato y Gregoria [fallecida el 27 de septiembre de 2005], que me enseñaron a amar la tierra y conservar la fe». Es el tercero de los cuatro libros de Revuelta que reproducen exclusivamente, a veces con algunas adiciones o complementos, artículos inéditos o ya publicados del propio Manolo. Los dos primeros recogen artículos de su especialidad. El primero se titula: La Iglesia española en el siglo XIX. Desafíos y respuestas (Revuelta, 2005). El segundo libro, Once calas en la Historia de la Compañía de Jesús, "Servir a todos en el Señor» (Revuelta, 2006) está dedicado a la Compañía de Jesús, que entonces celebraba los 450 años de la muerte de San Ignacio. El cuarto, el citado Enigmas históricos de la Iglesia española contemporánea (Revuelta, 2017a).

\subsection{Artículos de Revuelta de temática palentina en libros colectivos}

En libros colectivos Revuelta publicó síntesis históricas de las que había quedado especialmente satisfecho, como la Iglesia española durante la crisis del antiguo régimen (tomo V de la Historia de la Iglesia en España dirigida por el padre Ricardo García Villoslada), la religión en las épocas del romanticismo y de la restauración (tomos 35 y 36 de la Historia de España de Menéndez Pidal-Jover), la Compañía de Jesús restaurada y renovada, en el libro coordinado por Teófanes Egido (Revuelta, 2004) y la historia de la Universidad Comillas, en el libro de su centenario, editado por Eusebio Gil (Revuelta, 1993).

Sobre un total de unos 70 artículos en libros colectivos, una docena son de temática palentina, siendo el primero «Configuración territorial de la provincia de Palencia en el siglo XIX» (Revuelta, 1982a) y el último «La Bailía de Población de Campos o de las Nueve Villas de Campos» (Revuelta, 2003), 
aunque el simposio sobre la Orden de San Juan en España se había celebrado en Madrid en 1990.

En el intervalo Revuelta participó en los tres congresos de Historia de Palencia celebrados, en los que habló, sucesivamente, de tres actividades religiosas de la diócesis en tres momentos distintos: en tiempos del obispo don Juan Lozano (Revuelta, 1987), don Enrique Almaraz (1893-1907) (Revuelta, 1990) y los prelados del reinado de Alfonso XIII (Revuelta, 1995). También colaboró en la Historia de Palencia dirigida por Julio González (Revuelta, 1984) y en la coordinada por Pablo García Colmenares (Revuelta, 1996).

\subsection{Artículos de Revuelta sobre Palencia en Revistas.}

En el recuento de Enigmas históricos (Revuelta, 2017a), aparecen 120 artículos en revistas a los que hay que añadir otra media docena aparecidos a lo largo de sus dos últimos años de vida. Al menos dos docenas de artículos son de temática palentina.

Bajo el apartado de los artículos caben toda clase de escritos muy diferentes por su tamaño, estilo y mérito. El recuento parece un cajón de sastre, pues se mezclan trabajos largos de investigación con artículos de vulgarización y con colaboraciones cortas y ocasionales para cumplir, en unas páginas, el compromiso de una revista o la invitación de una hoja parroquial. El tamaño y calidad científica de un artículo o de un libro no siempre se corresponde con la satisfacción del autor. Las piezas menores son a menudo pequeñas joyas para el autor por su valor sentimental. Por eso, Revuelta incluye en la lista los primeros artículos suyos que aparecieron en letras de molde entre 1950 y 1957 (Revuelta, 1959; 1956; 1957) ${ }^{6}$, siendo niño, o joven sacerdote en Alemania (Revuelta, 1965).

La revista Publicaciones de la Institución Tello Téllez de Meneses de Palencia (PITTM) será donde aparecerá la mayor parte de la historiografía palentina de Revuelta, con una fidelidad que duró desde 1971 hasta 2018. En sus Memorias nos narra cómo empezó a interesarse por la Historia de Palencia y su primer contacto con la PITTM para publicar sus primeras investigaciones (Pérez García, 2019). Todo comenzó, a finales de la década de 1960-1970, preparando la tesis doctoral. En ratos libres consultaba los documentos de la Orden de Malta sobre la Bailía de Población de Campos, obteniendo magníficos resultados. Con ellos escribió el artículo en el que se pasa revista

\footnotetext{
6 El primero cuando era estudiante de bachillerato en el Colegio de San José de Valladolid y el segundo, de Humanidades en Salamanca; el tercero apareció en una hoja parroquial.
} 
a los 37 pueblos donde la Bailía tenía posesiones en la zona sur, más las 14 localidades de la zona norte (Montaña Palentina y Cantabria). De estos lugares, empezando por Arbejal, sacó 27 fotografías (alguna de una iglesia desaparecida, como la de Monte en Santander) que ilustran el artículo (Revuelta, 1971). Como complemento de la Bailía escribió otro artículo centrado en su pueblo, Población de Campos, «Noticias históricas de la ermita de Nuestra Señora del Socorro» (Revuelta, 1973), con 16 fotografías, publicado cuando se estaba restaurando la ermita. Envió el artículo de la Bailía a don Jesús San Martín Payo, un académico fundador de la ITTM en 1949, sabio canónigo palentino, que había sido amigo de su padre, pues coincidieron en el seminario. Tardó un poco en contestarle, pero al fin lo hizo, suponiendo que era hijo de su amigo Fortunato. Don Jesús será siempre su valedor. Hizo recensiones muy elogiosas de los primeros libros de Revuelta; y sin duda influyó en su nombramiento de académico de la Academia Palentina el 4 de mayo de 1992. Don Jesús se encargó del discurso de recepción, que no pudo pronunciar, pues murió unos días antes. Era un discurso al mismo tiempo elogioso y cariñoso, con el recuerdo expreso de su padre Fortunato. Lo leyó don Mariano Fraile Hijosa, otro canónigo amigo, académico entre 1965 y 2011 (Pérez García, 2019).

Curiosamente el último artículo palentino de Revuelta (2017b) versará sobre «El altar mayor de la iglesia de Santa María Magdalena de Población de Campos", que había sido restaurado por la madre de Manolo, y aparecerá en 2017 en PITTM. En el intervalo, en la misma revista, se van publicando relevantes artículos palentinos, como «La desamortización eclesiástica en Aguilar de Campoo» (Revuelta, 1979), "La villa de Frómista en dos momentos de su historia» (Revuelta, 1987b). En dicha revista se publicó su discurso de recepción en «La Tello», el 4 de mayo de de 1992, que versó sobre Origen, ocaso y renovación de los conventos palentinos (Revuelta, 1992) ${ }^{7}$, que recordará en sus Memorias con emoción ( «Tengo la satisfacción de que estuvieron presentes mi madre y mis tíos»), el único honor académico que Revuelta aceptó, puesto que rehusó el de académico correspondiente de la Historia, cuando Felipe Ruiz Martín se lo ofreció, a quien Revuelta (2000) corresponderá agradecido con una semblanza.

Revuelta (1999) tardará siete años en publicar otro artículo relevante en la PITTM («La recuperación artística en Palencia») y dos años más tarde pronunciará el discurso de apertura del curso académico 2000-2001

7 Se imprimió también en publicación separada: Origen, ocaso y renovación de los conventos palentinos. Discurso con motivo de la recepción en la Institución Tello Téllez de Meneses, el día 4 de mayo de de 1992, y contestación al discurso del nuevo académico por Don Jesús San Martín Payo. Palencia, 1994. 
(«Finanzas y poesía: México y Palencia a través de la familia Mier y Pesado» (Revuelta, 2001)). Entre 2003 y 2005 Manolo estudia a personajes palentinos que organizaron sindicatos campesinos católicos, como el abogado Antonio Monedero Martín (Monedero, 2003) o el P. Sisinio Nevares (Revuelta, 2005), saliendo de las prensas de PITTM en sendos estudios.

Entre 2005 y su muerte, salvo el ya citado artículo de 2017 sobre el altar mayor de Población de Campos (Revuelta, 2017b), sólo encontramos en PITTM los «Aspectos religiosos de la Guerra de la Independencia y sus repercusiones en Palencia» (Revuelta, 2008).

\subsection{Prólogos de Revuelta en libros Relacionados con Palencia}

Aunque Revuelta solía decir que los escritores viejos escriben cada vez menos libros y más prólogos, en el recuento de Enigmas históricos (Revuelta, 2017a) figura media docena de prólogos a libros ajenos relacionados con Palencia, desde bastante pronto, siendo el primero en el libro Palencia en la Historia (Revuelta, 1982b), signo evidente de que ya era profeta en su tierra y sus paisanos reconocían su mérito. El último aparece en 2008, Palencia, aprendiz de capital, de Rafael del Valle Curieses (Revuelta, 2008). El resto son presentaciones o prólogos a historias locales, como la Flechilla de Francisco Herreros Estébanez (1984) o la de la comarca Boedo-Ojeda de Roberto Gordaliza y Miguel Ángel Ortiz (2004).

Son breves apuntes que no suelen sobrepasar las cinco páginas, destacando los dos prólogos que antepuso a sendos libros de Luis Fernández Martín (1981) y Jesús Sanjosé del Campo (2007) sobre el Colegio de San José de Valladolid, del que tantas vocaciones jesuitas palentinas salieron, como la de Goyo Ruiz o la del mismo Revuelta (Astorgano, 2020). Además, Manolo tenía una antigua relación personal con Luis Fernández por ser su primer orientador hacia su vocación como historiador, cuando siendo estudiante de Filosofía en Comillas, el P. Provincial de León, José Cobreros, encargó al P. Luis Fernández que hablase con los estudiantes que terminaban la Filosofía, para decidir si convenía orientarlos a estudios especializados:

Luis Fernández, palentino de Villarramiel, era historiador y había sido profesor mío en [el colegio de San José] Valladolid. ¿Qué aficiones tienes, Revuelta?, me preguntó. Y yo le dije: me gusta la Historia. Su recomendación al P. Provincial debió de influir para que me mandaran a estudiar la carrera de Historia en Santiago de Compostela (discurso citado de 17 de noviembre de 2011). 
Al también jesuita Sanjosé del Campo, Revuelta le había dirigido en 2006 una espléndida tesis doctoral sobre «Temática educativa en la revista Razón y Fe durante el franquismo», revista de la que llegará a ser director.

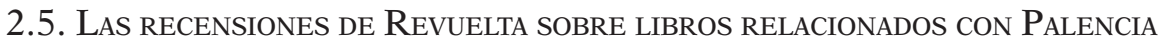

De los dos centenares largos de recensiones, redactadas por Revuelta a lo largo de su vida, una treintena son de libros que versan sobre la Historia de Palencia. No parece darle mayor importancia: «La lista de las recensiones es la más numerosa. Toda revista que se precie debe publicar recensiones, género difícil, comprometido y sujeto a límites de espacio. En mi lista abundan las recensiones largas» (Revuelta, 2017a, pp. 17-18). En sus Memorias, se limita a decir: «Publiqué también muchas recensiones sobre bibliografía palentina, que no es cuestión de reseñar»(Pérez García, 2019).

Todos conocemos a prestigiosos historiadores que teniendo centenares de publicaciones, apenas redactan recensiones para no «contaminarse» con tan difícil género, que suelen rentar poco académicamente y ocasionar alguna que otra enemistad, si son sinceras. Por el contrario, Revuelta manifestaba su silenciosa generosidad con centenares de recensiones, generalmente comprensivas y estimulantes.

No procede que enumeremos estas recensiones, que cronológicamente abarcan desde 1969 hasta 2019. Sólo lo haremos con algunas de tema palentino que nos han llamado la atención. La primera apareció en Miscelánea Comillas en 1976 sobre la Silva Palentina de A. Fernández de Madrid (1976), nuevamente editada por Jesús San Martín Payo, el sabio canónigo palentino, que había sido amigo del padre de Revuelta, pues coincidieron en el seminario, y que había propiciado sus primeras publicaciones en PITTM (Revuelta, 1973).

Sorprende que Revuelta no publicase reseñas en su querida PITTM hasta 2001, cuando ya habían aparecido más de un centenar en otras revistas, generalmente eclesiásticas. Pero desde ese año hasta su muerte publicará en la misma una veintena de recensiones, es decir, raro es el año que no insertaba alguna. Así, de la docena de reseñas suyas redactadas entre 2017 y 2019, la mayoría fueron a parar a las revistas jesuíticas, Estudios Eclesiásticos, Razón y Fe, y Miscelánea Comillas, pero reservó dos para PITTM, sobre sendos libros de José María Pérez González, «Peridis» (2017) y de León Palenzuela (2018). En medio apareció una quincena de reseñas, bastante amplias (de 3 a 5 páginas) de diversa temática, como heráldica de pueblos palentinos (Narganes 
Quijano, 2001; Viguri, 2005), el importante Diccionario histórico de la Compañia de Jesús. Biográfico y temático (O’Neill, Ch., J. M. Domínguez, 2001), la historia del la Guerra Civil y primer Franquismo (Colmenares, 2007) o la historia del carbón palentino (Narganes, 2010).

\section{REVUELTA Y LA INSTITUCIÓN TELLO TÉLLEZ DE MENESES (ACTUAL ACADEMIA PALENTINA DE HISTORIA, LETRAS Y BELLAS ARTES)}

Fue la institución a través de la cual Revuelta canalizó la mayor y mejor parte de sus investigaciones sobre su provincia natal. Como hemos visto, en La Tello (PITTM) publicó muchos artículos y reseñas y pronunció varias conferencias. Lógicamente las relaciones se estrecharon a partir de su incorporación como académico de número en 1992, apadrinando Revuelta el ingreso de competentes historiadores, como el modernista Alberto Marcos Martín, cuyo discurso de contestación pronunció el el día 30 de mayo de 2003 (Revuelta, 2003).

Le gustaba recordar en sus Memorias a los amigos y favorecedores palentinos que apadrinaron su ingreso:

Sin duda influyó también en mi nombramiento [como académico de la ITTM en 1992] Maritina Calleja, que entonces era Delegada de Cultura de la Diputación, presidida por don Jesús Mañueco. Seguramente influyó también en mi nombramiento mi charla en la Casa de Palencia, en el ciclo que allí organizamos sobre nuestra historia. Mi aportación fue sobre «La configuración territorial de la provincia de Palencia en el siglo XIX» [Revuelta, 1981; 1982a], en la que se recorrían las vicisitudes sufridas por la provincia, cuando en 1822 se la quiso sacrificar repartiéndola entre Burgos, Valladolid y León. Añadí un documento muy significativo del palentinismo que ya entonces mostraron los pueblos de todas las comarcas (Pérez García, 2019).

Las conferencias fueron publicadas por la Caja de Ahorros en 1982, con una introducción del mismo Revuelta (1982a; 1982b). Previamente, la charla se había tenido con mucho éxito en la Diputación de Palencia y en Aguilar de Campoo (Revuelta, 1981).

También tuvo entonces varias charlas históricas en los pueblos. En Frómista, escogiendo dos momentos históricos; en Aguilar sobre la desamortización y sobre el arte perdido y hallado en la provincia; en Población de Campos sobre la restauración de la iglesia; en Carrión de los Condes sobre el 
P. Nevares y en Dueñas sobre el citado don Antonio Monedero, organizador de sindicatos campesinos católicos (Pérez García, 2019).

En dichas Memorias Revuelta resume la historia de la actual Academia Palentina y, una vez más, confiesa su cariño por dicho organismo en un gratificante excurso. La Institución Tello Téllez de Meneses siempre representó muy bien la cultura palentina, por su revista (PITTM) y sus publicaciones. Fue fundada en 1949. Lleva el título del obispo don Tello, que convirtió los estudios generales de la Catedral en la primera universidad de España. A lo largo de su existencia el número de numerarios ha sido 61. Hoy son 23. Al principio dependía de la Diputación Provincial, siendo su presidente también el de la Institución. En aquellos años el 30 de mayo se celebraba misa en el altar de San Fernando en la catedral; seguido de un ágape fraternal. Los primeros estatutos de 1949 recibieron alteraciones accidentales en 1977, 1983, 1988 y 2001. En el año 2012 se alteró sustancialmente el reglamento, para ajustarlo a lo dispuesto por la Junta de Castilla y León, para arreglar las academias científicas y culturales de la Comunidad. Desde entonces se ha independizado de la Diputación y se ha secularizado (ya no se celebra San Fernando). Mantiene su titulación (familiarmente «La Tello»), añadiendo el subtítulo de Academia Palentina de Historia, Letras y Bellas Artes. La Diputación sigue aportando ayudas económicas, pero no corre con todos los gastos (Pérez García, 2019).

Humilde y agradecido, Revuelta fue generoso con los historiadores palentinos y con la ITTM, renunciando a los honores de la Real Academia de la Historia, a favor de colegas más jóvenes, según relata en sus Memorias:

Cuando hicimos el homenaje al académico don Felipe Ruiz Martín, me propuso nombrarme académico correspondiente de la Historia [Revuelta, 2000] ${ }^{8}$. Yo le dije que era mejor que se otorgase ese honor a quienes residían en Palencia y le propuse a Rafael Martínez y Faustino Narganes ${ }^{9}$. Así se hizo. Por último quiero recordar el apoyo del entonces presidente de la Diputación, Enrique Martín, que añadió 200.000 pesetas a la dotación de mi madre para restaurar el altar mayor de mi pueblo y el encargo de Rafael Martínez a la empresa Fénix Conservación, de Burgos, que lo realizó perfectamente (Pérez García, 2019).

Una vez más la humildad privó a Revuelta de los honores académicos, pues era mucha la influencia del prestigioso historiador económico Felipe Ruiz Martín (1915-2004). Dejó pasar la oportunidad de instalarse en la RAH y no volvió otra, a pesar de sus sobrados méritos.

8 En justa correspondencia, Revuelta (2000) publicó una semblanza del académico: «El historiador Don Felipe Ruiz Martín».

9 Los académicos de la ITTM Rafael Ángel Martínez González (*11-11-1954) y Faustino Narganes Quijano (*17-2-1948). 


\section{UN RESUMEN MUY PERSONAL}

De lo expuesto hasta ahora pensamos que el lector puede esbozar una imagen clara de la vinculación de Revuelta con la historia de la Provincia de Palencia. Para finalizar nos atrevemos a ilustrar esa imagen con nuestra experiencia personal. Desde que confluimos en 2010 en el estudio del jesuita expulso palentino Juan José Tolrá, con frecuencia Revuelta me insinuaba que preparase un estudio sobre el mismo para la revista PITTM. Por distintos compromisos no pude acceder a sus deseos, aunque íbamos acumulando documentación sobre el dicho P. Tolrá. Casi todo lo que Revuelta opinaba sobre el restaurador palentino P. Tolrá lo había dicho en el congreso de 2011 (Revuelta, 2012), estimulándome a que continuase yo las investigaciones sobre el mismo, como hice en los ocho artículos citados (Astorgano, 2015; 2016a; 2016b; 2017a; 2017b; 2018; 2019a; 2019b).

Revuelta admiraba a Tolrá por ser palentino, por encarnar el espíritu restaurador de la Compañía y por atreverse a representar a las Cortes pidiendo justicia contra la política anti jesuítica de Carlos III. Que a Revuelta le apasionaba el tema de la Compañía restaurada es obvio, pues dedicó toda su vida a estudiarlo y culminó con un precioso y sintético libro (Revuelta, 2013), en el que, al hablar de la restauración del Noviciado de Madrid en 1816, narra que en dicho noviciado se formaba una numerosa juventud acompañada por un grupo de seis o siete sacerdotes veteranos, «entre cuyos animosos ancianos se destacaba el P. Juan José Tolrá, que se había hecho célebre por el Memorial que dirigió a las Cortes de Cádiz, pidiendo un juicio justo de la Compañía» (Revuelta, 2013, p. 280).

En mayo de 2016 Revuelta volvió a inspirar otro congreso más reducido y específico sobre «La Restauración de la Compañía de Jesús en España (1815-1835)», y me invitó insinuándome que hablase sobre Juan José Tolrá, y lo hice sobre «El P. Tolrá (1739-1830) o la conciencia restauradora de la Compañía» (Astorgano, 2016a). Me consta que le agradó mi ponencia, lo cual demostró en los sucesivos coloquios, destacando el nivel de todas las disertaciones y «la peculiaridad de Tolrá». Ese mismo año publiqué en Studium Ovetense «La poesía religiosa del jesuita expulso Juan José Tolrá (1739-1830)», a él dedicado (Astorgano, 2016b) y me volvió a insistir en que publicase algo en PITTM. El 1 de enero de 2016 Manolo había cumplido 80 años y en carta del 4 de mayo me comenta por primera vez los síntomas de su enfermedad, aunque continuaba animoso para cumplir varios compromisos (como siempre relacionados con el servicio a la Compañía y a su nativa Palencia), sin faltar el consejo académico del amigo, a pesar de haber «colgado los trastos»: 
Ya veo que le señalas una etapa en Palencia [en la biografía de Tolrá], que puede darte, como te dije, para un articulito para PITTM. Si incluye la poesía al Cristo del Otero (que no sería el de Victorio Macho), mejor; pero tómatelo con calma, cuando buenamente puedas y sin ningún agobio.

Como presintiendo la gravedad de su enfermedad, a lo largo de 2017 nuestra correspondencia se hizo más frecuente y procuré seguir más fielmente sus insinuaciones. Tan pronto como la coordinación del bicentenario de la muerte de Meléndez Valdés me dio un respiro (Astorgano, 2017c), redacté el artículo para la PITTM (Astorgano, 2017b), dedicado a él («palentino de pro» $)^{10}$, lo cual alegró mucho a Manolo, como demuestra la generosa evaluación que hizo del mismo y me remitió, para mi satisfacción, en carta del 26 de mayo de 2017. No sólo da su aprobación, sino que soluciona con la revista los dos problemas evidentes de mi artículo: su excesiva extensión y la falta de unidad temática, puesto que pretendía presentar a los palentinos la polifacética personalidad de Tolrá, ilustrada con dos textos poéticos importantes:

Querido Antonio:

Me piden de Palencia mi parecer sobre el artículo que enviaste sobre el P. Tolrá para su publicación en la revista de La Tello. Les he contestado lo siguiente:

Querida Esther:

Recibo el artículo del profesor Antonio Astorgano sobre el P. Juan José Tolrá, y la petición de mi informe con vistas a su publicación en PITTM.

Don Antonio Astorgano Abajo es el mejor conocedor de los jesuitas exiliados por la expulsión de Carlos III, entre los que se destacó el P. Tolrá. Yo mismo le pedí al autor que escribiera algo sobre el P. Tolrá para PITTM. Últimamente (con motivo de su artículo sobre el mismo padre en Studium Ovetense ${ }^{11}$ ) le animé a que publicara en nuestra revista el poema dedicado al Cristo del Otero. El autor ha respondido rápidamente con el excelente artículo que os ha enviado, en el que presenta al jesuita como "restaurador de las Humanidades", analizando no solo la poesía al Cristo del Otero, sino también el poema en dísticos latinos sobre la restauración de los estudios humanísticos. Ambas poesías se compaginan la una con la otra, de manera que el artículo forma una unidad.

[...] Astorgano analiza y comenta este texto inédito [los dísticos latinos] con gran competencia profesional, mientras va traduciendo el texto latino al castellano. Teniendo en cuenta todos estos méritos, aconsejo vivamente que se publique el artículo del profesor Astorgano en PITTM....

[...]

Espero que no haya dificultades en la publicación. Por mi parte te agradezco una vez más esta contribución tan valiosa en la revista palentina, y la dedicatoria que me haces (no sin cierto rubor por mi parte) al "palentino de pro». Un fuerte abrazo. Manuel Revuelta SJ.

10 Por cierto, la dedicatoria fue suprimida en la edición impresa.

11 Revuelta alude a: Astorgano (2016b). 
El 13 de junio me comenta: «Me dijeron de Palencia que tu artículo saldrá en el próximo Número de PITTM. Ya contábamos con ello, y por eso no te avisé». El 7 de septiembre me dice que «El día 16 de agosto [2017] me hicieron un homenaje en mi pueblo que salió muy bien».

No voy a repetir que la actividad investigadora de Revuelta estuvo presidida por el rigor científico, y que su generosidad implicaba a sus amigos en las tareas historiográficas que lo entusiasmaban. Por eso mi breve encuentro con la Historia de Palencia, propiciado por Manolo, permanece grato y sólo hace aumentar mi lamento por su ausencia.

\section{SIGLAS Y REFERENCIAS}

\section{SigLAS}

PITTM: Publicaciones de la Institución Tello Téllez de Meneses.

ITTM: Institución Tello Téllez de Meneses.

UPCo: Universidad Pontificia Comillas.

\section{REFERENCIAS}

Astorgano, A. (2010). Los jesuitas expulsos frente al proceso revolucionario antes de la promulgación de la Constitución de Cádiz: El ex jesuita oprimido. En M. Koprivitza Acuña, M. Ramos Medina, C. Torales Pacheco, J. M. Urkía y S. Yano Bretón (eds.). Del mundo hispánico a la consolidación de las naciones. 1808-1940 (pp. 237-281). Tlaxcala: Gobierno del Estado de Tlaxcala.

Astorgano, A. (2011). Un jesuita expulso sangüesino rebelde: Francisco Javier Mariátegui, el exjesuita oprimido. Príncipe de Viana, 72, 181-252.

Astorgano, A. (2012). El mito de la perfección clásica en Vicente Requeno (17431811) y su fracaso en España (el encausto). En J. Martínez Millán, H. Pizarro Llorente y E. Jiménez Pablo (Coords.). Los jesuitas: religión, política y educación (siglos XVI-XVIII) (pp. 863-924). Madrid: UPCo.

Astorgano, A. (2015). El jesuita expulso extremeño Juan José Tolrá frente a la Constitución de Cádiz. Trienio, Ilustración y Liberalismo, 65(1), 5-81.

Astorgano, A. (2016a). El P. Tolrá (1739-1830) o la conciencia restauradora de la Compañía. En H. Pizarro y A. Verdoy (Coords.). La Restauración de la Compañía de Jesús en España (1815-1835). Madrid: UPCo (no se publicaron las actas).

Astorgano, A. (2016b). La poesía religiosa del jesuita expulso Juan José Tolrá (17391830). Studium Ovetense, 44, 135-245.

Astorgano, A. (2017a). El paludismo en Palencia (1800-1804) a través del Canto votivo del jesuita Tolrá. Asclepio, 69(1), 45-79. 
Astorgano, A. (2017b). El palentino P. Tolrá (1739-1830), restaurador de las Humanidades en la Compañía de Jesús (1815-1830). PITTM, 88, 185-209.

Astorgano, A. (2018). El P. Tolrá, mentor de la restaurada Compañía de Jesús (18121820). Trienio. Ilustración y Liberalismo, 71(1), 81-128.

Astorgano, A. (2019a). Las raíces de los Tolrá, guerreros antibolivarianos. El P. Tolrá y el humanismo en la Compañía de Jesús restaurada (1812-1830). Montalbán, Revista de Humanidades y Educación, 54(2), 10-258.

Astorgano, A. (2019b). El jesuita expulso Juan José Tolrá, innovador del «canto votivo». Trienio. Ilustración y Liberalismo, 73(1), 67-109.

Astorgano, A. (2020). Manuel Revuelta, un historiador de la Compañía de Jesús ejemplar. In memoriam. Montalbán, Revista de Humanidades y Educación, 55(1), 3295.

Astorgano, A. (coord.) (2017c). Homenaje a Juan Meléndez Valdés en el bicentenario de su muerte (1754-2017). Revista de Estudios Extremeños, 73 ( ${ }^{\circ}$ Extraordinario), 2 vols.

Fernández de Madrid, A. (1976). Silva Palentina. Palencia. Reseñada por M. Revuelta en Miscelánea Comillas, 51 (1976), 282-283.

Fernández Martín, L. (1981). Historia del Colegio San José de Valladolid. Valladolid. Prólogo de Revuelta, 9-32.

García Colmenares, P. (coord.) (2007). Historia y memoria de la Guerra Civil y primer Franquismo en Castilla y León. Valladolid. Reseñada por Revuelta en PITTM 79 (2008).

González, J. (dir.) (1984). Historia de Palencia, v. II. Edades moderna y contemporánea. Palencia: Diputación Provincial.

Gordaliza Aparicio, F. R. y Ortiz Nozal, M. A. (2004). Boedo-Ojeda y Ribera. Apuntes de Historia, Arte y Toponimia. Palencia.

Herreros Estébanez, F. (1984). Historia de Flechilla. Palencia: Diputación.

Hervás y Panduro, L. (2007). Biblioteca jesuítico-española. Madrid: Libris.

León Palenzuela, G. (2018). Catolicismo Social en Palencia. La trayectoria política y social de Ricardo Cortes Villasana entre 1909 y 1936. Palencia: ITTM, 2018. Reseña de Revuelta en PITTM, 89 (2018), 321-325.

Mariátegui, F. J. (1812). El Ex Jesuita oprimido. Memoria que presenta a su Majestad, la Junta de Cortes el ex jesuita F. X. M. Palma: Oficina de Brusi.

Martínez Millán, J., Pizarro Llorente, H. y Jiménez Pablo, E. (Coords.) (2012). Los jesuitas: religión, política y educación (siglos XVI-XVIII). Madrid: UPCo.

Monedero Martín, A. (2003). Siete años de propaganda (Crónicas de «Juan Hidalgo»). Estudio introductorio por Manuel Revuelta. Palencia: ITTM.

Narganes Quijano, F. (2001). Lantadilla (Palencia): breves noticias históricas para la adopción de su escudo y bandera municipal. Palencia. Reseña de Revuelta en PITTM, 73 (2002), 449-451.

Narganes Quijano, F. (2010), Historia del carbón de antracita en la Montaña Palentina. Palencia. Reseña de Revuelta en PITTM, 81(2010), 463-466.

O’Neill, Ch., y Domínguez, J. M. (coords.) (2001). Diccionario histórico de la Compañia de Jesús. Biográfico y temático. Madrid: UPCo. Reseñado por Revuelta en PITTM, 73(2002), 452-456. 
Pérez García, A. (2019, junio 20). Necrológica del P. Manuel Revuelta. Recuperado de https//infosj.es.pdf 201927.

Pérez González, J. M. («Peridis») (2017). Hasta una ruina puede ser una esperanza. Monasterio de Santa María la Real de Aguilar de Campoo. Aguilar de Campoo: Monasterio de Santa María la Real de Aguilar de Campoo. Reseñado por Revuelta en PITTM, 89(2018), 313-316.

Revuelta, M. (1950, septiembre 10). El pescador. Vacaciones, Colegio de San José, 9, p. 3.

Revuelta, M. (1956), El libro V de la Eneida. Salamanca. Colegio de San Estanislao, 10 (mayo-julio), 8-14.

Revuelta, M. (1957, enero 5). Un niño nos ha nacido. Vía. Hoja Parroquial de Pravia, 1292, p. 1.

Revuelta, M. (1965, septiembre 4). Primera misa de un jesuita palentino en Alemania. Diario Palentino.

Revuelta, M. (1971). La Bailía de Población de la Orden de San Juan de Jerusalén. Publicaciones de la Institución Tello Téllez de Meneses de Palencia (PITTM), 32, 203-237.

Revuelta, M. (1973). Noticias históricas de la ermita de Nuestra Señora del Socorro de Población de Campos. PITTM, 34, 249-277.

Revuelta, M. (1979). La desamortización eclesiástica en Aguilar de Campoo. PITTM, 43, 173-208.

Revuelta, M. (1981). Orígenes históricos de la constitución de la Provincia de Palencia. Palencia: Diputación Provincial.

Revuelta, M. (1982a). Configuración territorial de la provincia de Palencia en el siglo XIX. En Palencia en la Historia (pp. 203-251). Palencia: Caja de Ahorros de Palencia

Revuelta, M. (1982b). Prólogo. En Palencia en la Historia (pp. 5-8). Palencia: Caja de Ahorros.

Revuelta, M. (1987). El resurgir de Palencia entre 1850 y 1920 y antecedentes: informes del obispo de Palencia, don Juan Lozano, a la Santa Sede sobre el estado de la diócesis. En Actas del I Congreso de Historia de Palencia: castillo de Monzón de Campos, 3-5 Diciembre 1985, Vol. 3, (Edad Moderna y Edad Contemporánea) (pp. 457-474). Palencia: Diputación Provincial.

Revuelta, M. (1990). La diócesis de Palencia durante el pontificado de D. Enrique Almaraz (1893-1907). En María V. Calleja González (coord.). Actas del II Congreso de Historia de Palencia, 27, 28 y 29 de abril de 1989, tomo II, vol. II. Edad Moderna y Edad Contemporánea (pp. 605-650). Palencia: Diputación Provincial.

Revuelta, M. (1987). La villa de Frómista en dos momentos de su historia. PITTM, $56,31-58)$.

Revuelta, M. (1992). Origen, ocaso y renovación de los conventos palentinos. PITTM, $63,47-84$

Revuelta, M. (1993). El seminario y Universidad de Comillas: De la Cardosa a Cantoblanco (1881-1972). En E. Gil Coria (ed. lit.). La Universidad Pontificia Comillas: cien años de historia [1892-1992] (pp. 17-152). Madrid: UPCo.

Revuelta, M. (1995). Iglesia y sociedad en Palencia en el reinados de Alfonso XII. En M. V. Calleja González (coord.). Actas del III Congreso de Historia de Palencia.30, 
31 de marzo y 1 de abril de 1995, Tomo III, Edad Moderna y Edad Contemporánea (pp. 323-386). Palencia: Diputación Provincial.

Revuelta, M. (1996). Iglesia, religiosidad tradicional y disidencias. En P. García Colmenares, J. Moreno Lázaro y J. L. Sánchez García (coords.). Historia de Palencia: siglos XIX y XX (pp. 289-300). Valladolid: El Norte de Castilla.

Revuelta, M. (1999). La recuperación artística en Palencia. PITTM, 70, 359-384.

Revuelta, M. (2000). El historiador Don Felipe Ruiz Martín. PITTM, 71, 503-508.

Revuelta, M. (2001). Finanzas y poesía: México y Palencia a través de la familia Mier y Pesado. PITTM, 72, 5-41.

Revuelta, M. (2003). Discurso de contestación al ingreso de Alberto Marcos Marín. PITTM, 74,105-113.

Revuelta, M. (2003). La Bailía de Población de Campos o de las Nueve Villas de Campos. En Actas del Primer Simposio Histórico de la Orden de San Juan en España. Toledo: Diputación Provincial, 429-433.

Revuelta, M. (2004). La Compañía de Jesús restaurada (1815-1965). La Compañía de Jesús renovada (1965-2003). En T. Egido (coord.). Los jesuitas en España y en el mundo hispánico (pp. 279-460). Madrid: Marcial Pons.

Revuelta, M. (2005). El P. Sisinio Nevares. Etapas de su acción social y promoción de los sindicatos agrarios palentinos. PITTM, 76, 355-393.

Revuelta, M. (2005). La Iglesia española en el siglo XIX. Desafíos y respuestas. Madrid: UPCo.

Revuelta, M. (2006). Once calas en la Historia de la Compañía de Jesús, «Servir a todos en el Señor». Madrid: UPCo.

Revuelta, M. (2008). Aspectos religiosos de la Guerra de la Independencia y sus repercusiones en Palencia. PITTM, 79, 155-178.

Revuelta, M. (2010). Historia y espíritu en tierras palentinas. Camino de Santiago y otros afanes. Palencia: Diputación Provincial.

Revuelta, M. (2012). Las Cortes de Cádiz y los jesuitas: encrucijada entre la antigua y la nueva Compañía. En J. Martínez Millán, H. Pizarro Llorente y E. Jiménez Pablo (Coords.). Los jesuitas: religión, política y educación (siglos XVI-XVIII) (pp. 1859-1906). Madrid: UPCo.

Revuelta, M. (2013). El restablecimiento de la Compañía de Jesús. Celebración de un centenario. Bilbao: Ediciones Mensajero.

Revuelta, M. (2015). Las tres estancias de Santa Teresa en Palencia. Palencia: ITTM.

Revuelta, M. (2017a). Enigmas históricos de la Iglesia española contemporánea. Madrid: UPCo.

Revuelta, M. (2017b). El altar mayor de la iglesia de Santa María Magdalena de Población de Campos. PITTM, 88, 255-269.

Revuelta, M. (2018). Semblanza del P. Quintín Aldea SJ (1920-2012). Anuario del Instituto de Estudios Zamoranos Florián de Ocampo, 33, 29-35.

Revuelta, M. et al. (1981). Orígenes históricos de la constitución de la provincia de Palencia. Palencia: Diputación Provincial.

Sanjosé del Campo, Jesús (2007). El Colegio San José. De la Ley General de la Educación a la LOGSE. Valladolid: Colegio de San José. Prólogo de Revuelta, 11-16.

Tolrá, J. J. et al. (1812). Memorial de los exjesuitas españoles a S. M. el Congreso de la Nación en sus Cortes generales y extraordinarias, sobre la nulidad e injusticia de 
la pragmática sanción de dos de abril de mil setecientos sesenta y siete para el extrañamiento de los mismos, y apertura que piden de su causa en tribunal competente y público. Santiago: Imprenta de los dos Amigos.

Valle Curieses, R. del (2008). Palencia, aprendiz de capital. Génesis de una capital de provincias. Palencia: Editorial Cálamo. Prólogo de Revuelta, 7-11.

Viguri, M. de (2005). Heráldica palentina, I y II. Palencia: Diputación. Reseña de Revuelta en PITTM, 77(2006), 443-446. 